\title{
Influence of Convex and Concave Curvatures in a Coastal Dike Line on Wave Run-up
}

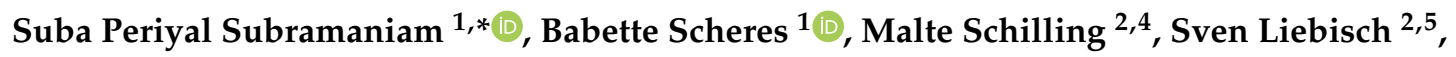 \\ Nils B. Kerpen ${ }^{2}\left(\mathbb{D}\right.$, Torsten Schlurmann ${ }^{2} \mathbb{( D}$, Corrado Altomare ${ }^{3} \mathbb{D}$ and Holger Schüttrumpf ${ }^{1}$ \\ 1 Institute of Hydraulic Engineering and Water Resources Management, RWTH Aachen University, \\ Mies-van-der-Rohe Straße 17, 52056 Aachen, Germany \\ 2 Leibniz University Hannover, Ludwig-Franzius-Institute for Hydraulic, Estuarine and Coastal Engineering, \\ Nienburger Straße 4, 30167 Hannover, Germany \\ 3 Laboratori d'Enginyeria Marítima, Universitat Politècnica de Catalunya-BarcelonaTech, C. Jordi Girona, 1-3, \\ 08034 Barcelona, Spain \\ 4 NLWKN Hannover-Hildesheim, An der Scharlake 39, 31135 Hildesheim, Germany \\ 5 Institute of Civil Engineering, University of Applied Science Kiel, Moorblöcken 12, 24149 Kiel, Germany \\ * Correspondence: subramaniam@iww.rwth-aachen.de
}

Received: 10 May 2019; Accepted: 20 June 2019; Published: 28 June 2019

\begin{abstract}
Due to climatic change and the increased usage of coastal areas, there is an increasing risk of dike failures along the coasts worldwide. Wave run-up plays a key role in the planning and design of a coastal structure. Coastal engineers use empirical equations for the determination of wave run-up. These formulae generally include the influence of various hydraulic, geometrical and structural parameters, but neglect the effect of the curvature of coastal dikes on wave run-up and overtopping. The scope of this research is to find the effects of the dike curvature on wave run-up for regular wave attack by employing numerical model studies for various dike-opening angles and comparing it with physical model test results. A numerical simulation is carried out using DualSPHysics, a mesh-less model and OpenFOAM, a mesh-based model. A new influence factor is introduced to determine the influence of curvature along a dike line. For convexly curved dikes $\left(\alpha_{d}=210^{\circ}\right.$ to $\left.270^{\circ}\right)$ under perpendicular wave attack, a higher wave run-up was observed for larger opening angles at the center of curvature whereas for concavely curved dikes $\left(\alpha_{d}=90^{\circ}\right.$ to $\left.150^{\circ}\right)$ under perpendicular wave attack, wave run-up increases at the center of curvature as the opening angle decreases. This research aims to contribute a more precise analysis and understanding the influence of the curvature in a dike line and thus ensuring a higher level of protection in the future development of coastal structures.
\end{abstract}

Keywords: curved dike; DualSPHysics; OpenFOAM; physical model tests; wave run-up

\section{Introduction}

Wave run-up and wave overtopping are decisive parameters not only for designing freeboards of coastal structures but also for the safety and rehabilitation of coastal structures, which helps to reduce the risk of failure. Due to the stochastic nature of wave processes, an exact description of wave run-up or overtopping is not possible. Hence, some empirical equations based on physical or numerical model tests help to determine wave run-up or wave overtopping. In those empirical formulas for wave run-up and wave overtopping suggested in the literature (EurOtop, 2018) [1], several factors based on the influences of berm, roughness, oblique wave attack and slope are already considered. However, geometrical characteristics like the curvature of the dike are not included.

Wave run-up is defined as the maximum wave run-up level, measured vertically from the still water line. For design purposes usually wave run-up level $R_{u 2} \%$ is used, which is exceeded by $2 \%$ 
of the number of incident waves (EurOtop, 2018) [1] (see Figure 1). The hypothesis is set if the wave run-up is influenced by the curvature in a dike line due to additional overlapping physical processes, i.e., refraction and diffraction. Yet there is limited information available on the influence of wave run-up on a curved dike and no detailed investigations have been done to include the factor based on curvature in the prediction formulae for wave run-up. The aim of this research is to provide an insight of wave run-up on a curved dike using numerical models validated with measurements from physical model tests. The numerical investigation is accomplished using DualSPHysics, a mesh-less model and OpenFOAM, a mesh-based model. Both of these numerical models are capable to simulate wave transformation, wave breaking and interaction with sloping structures, which made them a feasible alternative to experimental investigations to predict wave run-up numerically.

This study aims not only to discuss the influence of wave run-up on a curved dike but also to discuss the wave transformation processes on convex and concave curvature dikes for regular waves in contrast to linear dike profiles.

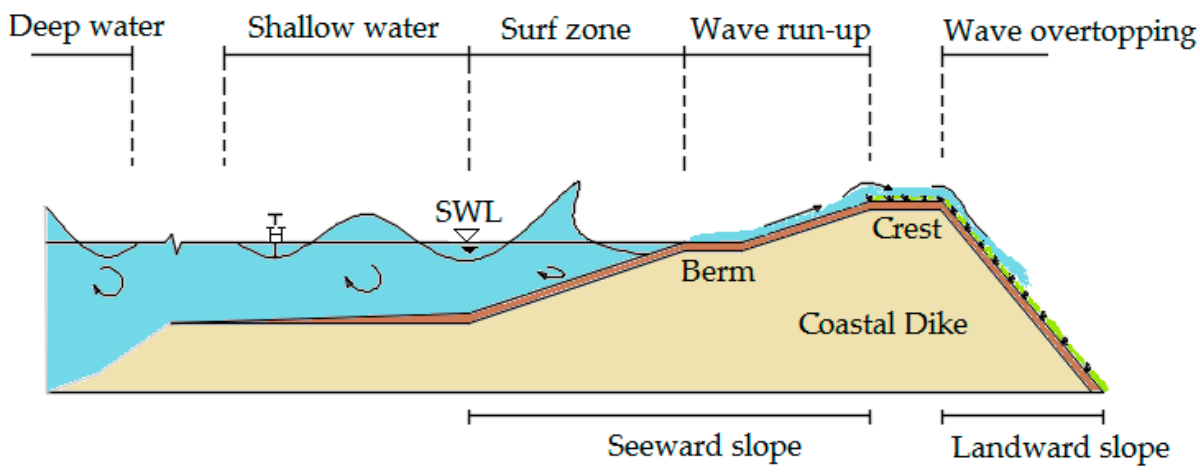

Figure 1. Definition sketch of wave run-up on coastal dikes.

\subsection{Influence of a Curvature in a Dike Line}

Coastal dike lines are bent concave (bent to the landside) and convex (bent to the seaside) due to local geographical conditions of the coastline or geological characteristics. Figure 2 shows the opening angle, $\alpha_{d}$ and opening radius, $r_{d}$ of a dike and they may influence the hydrodynamics of approaching waves. The opening angle, $\alpha_{d}$ is defined as the seaward angle between the tangents of the dike flanks. The opening radius, $r_{d}$ is defined as the distance between the meeting point of the perpendiculars of both dike flanks and the limit of the dike curvature.

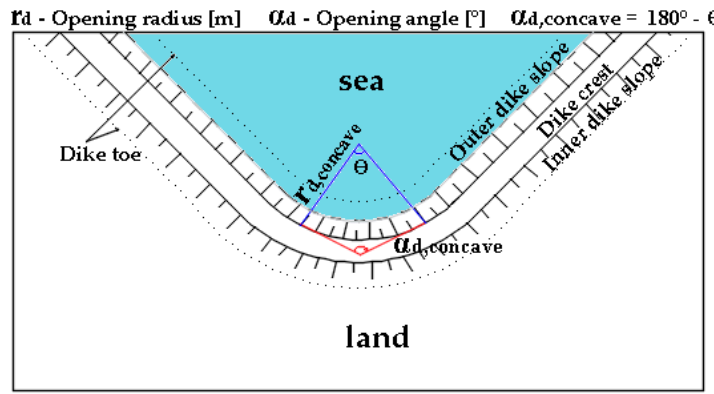

(a)

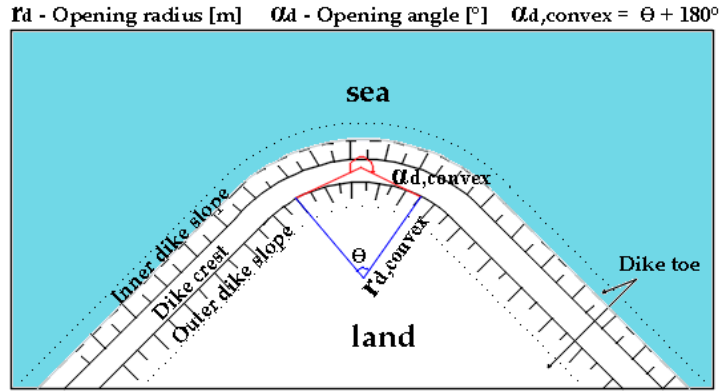

(b)

Figure 2. Definition sketch of opening angle, $\alpha_{d}$ and opening radius, $r_{d}$ of curvatures in a dike line. (a) concave curvature (b) convex curvature.

\subsection{Literature Review}

The contributions of Mayer at al. (1994) [2], Goda (2000) [3], Napp et al. (2004) [4], EurOtop (2018) [1] and Bornschein et al. (2014) [5] are among the earlier investigations on concave or convex profiles. Mayer et al. (1994) [2] attempted to predict run-up in concave profiles. They provided an 
analytical solution to estimate wave run-up in complex concave beach topographies by integrating Hunt's formula (1959) [6] with Saville's formula (1957) [7] and iterative solution for composite slopes. However, this iterative method is complex and requires a prior determination of the wave breaking point. Apart from Mayer et al. (1994) [2], Holman (1986) [8], Mase (1989) [9], Stockdon et al. (2006) [10] and Di Luccio et al. (2018a) [11] have done extensive research on wave run-up prediction and observation in natural beaches. In this paper, we would like to focus on wave run-up influence on coastal structures especially in a curved dike line. Goda (2000) [3] presented a numerical solution for the reflection effect on a concave seawall corner. According to his formulations presented, the wave height increases with a decreasing opening angle of the dike curvature and argued that this is due to the wave energy concentration inside a bay. Napp et al. (2004) [4] stated that there is lower overtopping rate at $90^{\circ}$ and $120^{\circ}$ concave corner in a vertical wall. He suggested that the observed decrease is due to the influence of combination of different wave breaking processes in combination with the effects of reflection and refraction. EurOtop (2018) [1] assumes that a concave curvature (with respect to the seaward face) could lead to an accumulation of wave energy, thus an increase in wave run-up and wave overtopping. On the other hand, for convex curvature (with respect to the landward face), EurOtop (2018) [1] assumes that the wave run-up and overtopping will decrease due to the distribution of wave energy. Bornschein et al. (2014) [5] observed visually a local increase in wave run-up and wave overtopping during a physical experiment model on a $270^{\circ}$ convex dike. Except for a few speculations, neither a mathematical expression that describes the effect of curvature nor an explanation on the hydrodynamic processes at curved dikes is available yet. Therefore, either an in-depth experimental or a numerical investigation is required to provide better understanding on the influence of curvature in a dike line on wave run-up of approaching waves.

\section{Numerical Model}

There are numerous computational models available to simulate hydrodynamic processes for coastal areas. However, very little software is suitable for this research due to the interaction of waves and structures, which involves many nonlinear phenomena like wave propagation, wave transformation, interaction among incident and reflected waves, wave breaking, wave run-up/run-down and wave overtopping. Numerical models based on the Navier-Stokes equation can be used to solve these complex phenomena. Thus, the software we chose to use for modelling wave run-up on a curved dike was DualSPHysics, a mesh-less model and OpenFOAM, a mesh-based model. An overview of the chosen software is described below.

\subsection{DualSPHysics}

DualSPHyics is based on the smoothed particle hydrodynamics (SPH) method (Crespo et al., 2015) [12]. Smoothed particle hydrodynamics (SPH) is a mesh free Lagrangian particle method and has special advantages in modeling complex fluid flows, especially those with fluid-structure interactions and large fluid deformations. SPH was first invented by Monaghan et al., 1977 [13] to solve astrophysical problems in the three-dimensional domain. For more than a decade now, there has been a lot of literature addressing the applications of SPH method in related areas. For instance, Meringolo et al. (2015) [14] has proposed SPH modeling for solid boundary conditions and validated for two test cases. Altomare et al. (2018) [15] has implemented a relaxation zone method, which acts as an internal wave maker and allows coupling DualSPHysics with any other model or analytical solution to generate sea waves. The previous research showed that DualSPHysics model can be compared with experiments with a high level of accuracy.

DualSPHysics is a mesh-less model where the fluid is discretized into set of particles, which possess material properties and interact with each other within the range controlled by a smoothing function. For each particle, the physical quantities such as velocity, density, pressure etc., are computed as an interpolation of the values of the neighboring particles. Wave generation is included in DualSPHysics for both regular and random waves. In this way, the numerical model can be used to simulate a 
physical wave flume or a wave basin. Both active and passive wave absorption can be implemented in DualSPHysics. However, active wave absorption is possible only for a piston-type wave maker. A damping zone is implemented in DualSPHysics as a passive wave absorption system. The model description, numerical simulation and results are described from Sections 4-6.

\subsection{OpenFOAM}

OpenFOAM (Open Source Field Observation and Manipulation) is used for various science and engineering applications and it is most suitable for complex fluid flow. OpenFOAM is based on the volume of fluid (VOF) method. To simulate free surface wave generation and absorption, a wave generation toolbox is available: Waves2Foam (Jacobsen et al., 2012) [16] and OlaFoam, an evolution of IHFOAM (Higuera et al., 2013) [17]. OpenFOAM in conjunction with olaFoam was assessed to be a suitable numerical tool for modeling wave run-up on dikes for 3D cases. OlaFoam provides the possibility to generate regular, irregular and solitary waves as well as the wave maker type. Active wave absorption is implemented to avoid reflections of waves from boundaries. The numerical simulations and results from OpenFOAM with olaFoam are described in detail from Sections 4-6.

For more details on the applied numerical software, the readers can refer to the respective user guides: the DualSPHysics user guide [18,19], OlaFoam manual [20], OpenFOAM user guide [21,22].

\section{Physical Model}

The wave-induced response of a curvature in the dike line was studied in physical model tests with a 1:6 sloping beach and in three general model set-ups- $(a, b)$ a straight geometry for reference; $(c, d)$ a convex geometry; and $(e, f)$ a concave geometry which have been contrasted in configuration. The models were constructed by an aluminum frame covered with plastic sheets (thickness: $5 \mathrm{~mm}$, surface roughness: smooth). Photographic impressions of the set-up and corresponding drawings are given (Figure 3 ). The tests were conducted in a multidirectional wave basin.

The basin had a test area of $30 \times 15 \mathrm{~m}$ over a horizontal floor. Waves were generated by a 72-element multidirectional wave maker including active reflection compensation routines on the long side of the basin. The three remaining boundaries of the basin were equipped with a passive eight-layer screen absorber.

The positions of the instrumentation described in the following are given in Figure $3 b, d, f$. The data acquisition was sampled with $100 \mathrm{~Hz}$ for all sensors. The incident wave conditions were measured with a six-gauge array in front of the dike. The six ultrasonic wave gauges (range: $0.2-1.2 \mathrm{~m}$, resolution: $0.18 \mathrm{~mm}$ ) in the array had a distance of $0.45 \mathrm{~m}$ to each other. Further wave gauges on the dike slope recorded the incident waves propagating onshore directed over the straight and curved slopes. Flow velocities were measured by acoustic Doppler velocimeters (accuracy: $\pm 1 \mathrm{~mm}$, sampling volume: $5 \times 6 \mathrm{~mm}$ ) at the toe of the slope. Capacitive wave run-up gauges (range: $0.2-4 \mathrm{~m}$, resolution: $10 \mathrm{~mm}$ ) provided data for each wave run-up event. They were located on the corners and on both straight wings of the model. The run-up height was calculated as median value out of 25 consecutive run-up events for regular waves. The corresponding interquartile range (IQR) is less than $10 \%$ from the median run-up value (see Figure A1). As some waves cause overtopping, the corresponding volumes were collected in up to five overtopping reservoirs (400-liter capacity each, inlet width: $0.3 \mathrm{~m}$ ) equipped with load cells (accuracy: $2 \mathrm{~N}$ ). The reservoirs were distributed along the crest of the dike and enabled a quantification of the mean overtopping discharge in the corner sections and on the straight wings of the model. In the present paper, the wave run-up data for regular waves are discussed and compared to the numerical findings. No comparisons are made for irregular waves due to the huge computational time in the numerical model. Wave overtopping and velocity results are not discussed in this paper. 


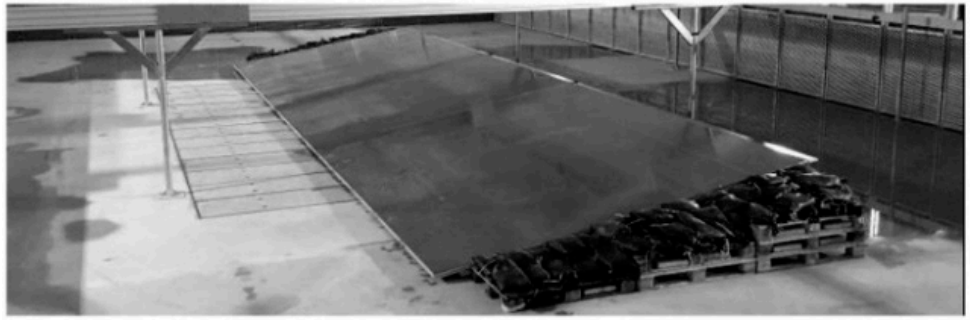

a)

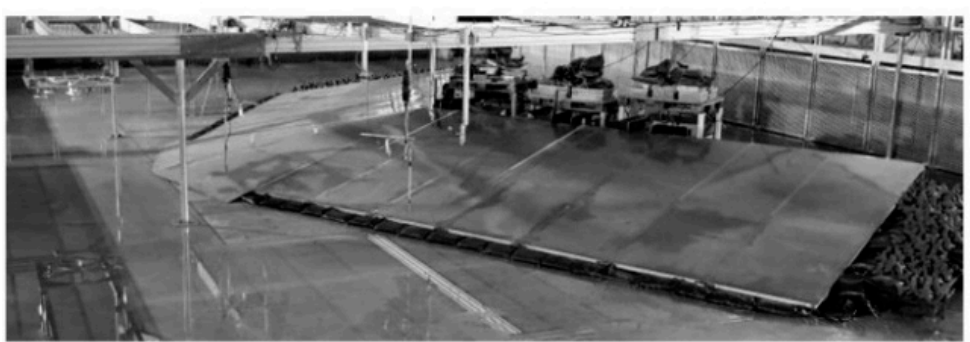

c)

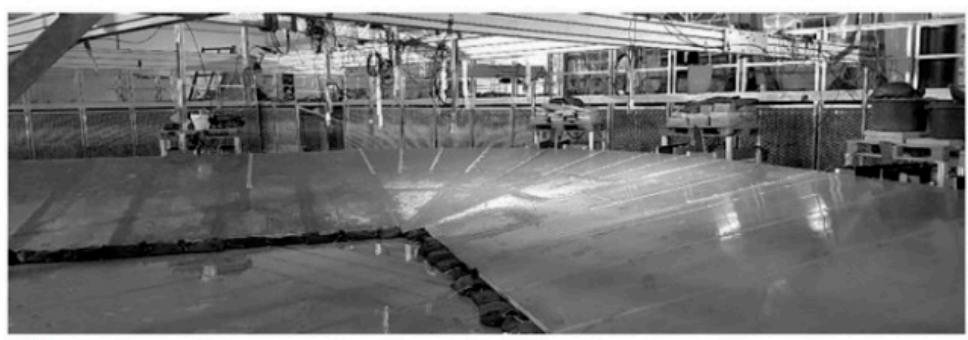

e)

Figure 3. Physical model set-up of the impermeable 1:6 sloped dike model in the wave basin with straight front $(\mathbf{a}, \mathbf{b})$, convex $(\mathbf{c}, \mathbf{d})$ and concave curvature $(\mathbf{e}, \mathbf{f})$. Sensor acronyms: Overtopping unit: $Q i$; velecity probe: $A D V i$; run-up gauge: $W P A i$; wave gauge: $A i$; camera: $C i$, and $i$ the sensor number.

The tested geometry configurations are given in Table 1. Corresponding wave conditions are listed in Table 2.

Table 1. Test configurations in the physical model.

\begin{tabular}{cccc}
\hline Curvature & Straight & Convex & Concave \\
\hline Opening angle $\alpha_{d}\left[^{\circ}\right]$ & 180 & 270 & $90 ; 120$ \\
Wave direction $\beta\left[^{\circ}\right]$ & $0 ; 30 ; 45$ & $-30 ;-15 ; 0 ; 15 ; 30 ; 45 ; 60$ & $-30 ;-15 ; 0 ; 15 ; 30$ \\
\hline
\end{tabular}

Tests were conducted with regular and irregular waves (long- and short-crested). The freeboard height $\left(1.0<R_{c} /\left(H_{m 0} \xi_{m-1,0}\right)<1.3\right)$, the Iribarren number $\left(0.7<\xi_{m-1,0}<1.4\right)$ and the angle of the incident waves (Table 1) were varied from test to test. For the present paper, results from regular waves only are given in Table 2 and are considered to contrast between numerical approaches. 


\section{Numerical Investigation on a Curved Dike Line}

To analyze the wave run-up and wave transformation processes on curved dikes, a simulation program with different opening angles and angles of wave attack for various wave parameters was investigated. Table 2 shows the wave parameters for regular waves used for the numerical simulation in both DualSPHysics and OpenFOAM. The different opening angles, $\alpha_{d}$ chosen for the simulation are $90^{\circ}, 120^{\circ}, 150^{\circ}, 180^{\circ}, 210^{\circ}, 240^{\circ}$ and $270^{\circ}$. The first three opening angles were tested for concavely curved dikes and the last three opening angles were tested for convexly curved dikes. The different angles of wave attack, $\beta$ included in the simulation are $0^{\circ}, 30^{\circ}$ and $45^{\circ}$, respectively.

Table 2. Wave parameters for the numerical simulation in DualSPHysics and OpenFOAM.

\begin{tabular}{ccc}
\hline Wave Height $\boldsymbol{H}[\mathrm{m}]$ & Wave Period $\boldsymbol{T}[\mathrm{s}]$ & Water Depth $\boldsymbol{d}[\mathrm{m}]$ \\
\hline 0.07 & 1.22 & 0.55 \\
0.10 & 1.46 & 0.55 \\
0.10 & 1.79 & 0.55 \\
\hline
\end{tabular}

\subsection{Calibration Study}

The calibration is done for a 3D numerical model for a straight dike on both OpenFOAM and DualSPHysics. Calibration simulations were performed and post-processed according to the boundary conditions and numerical settings for various wave parameters. DualSPHysics implements only water. The fluid was considered to be weakly compressible and the Tait's equation of state was employed, whereas OpenFOAM uses both air and water. The roughness was not modelled in DualSPHysics. Standard boundary conditions were used, which treated the boundary particles as fluid particles but fixed in space. For the boundary particles, the Navier-Stokes equations were solved as for the fluid particles. The effect of the diffusion scheme based on the so-called artificial velocity was employed to reduce model instability and numerical noise. In OpenFOAM, the roughness was considered by means of the wall functions used with the K-E turbulence model. The results were compared in accordance with Hunt's formula (1959) [6] (see Figure 4).

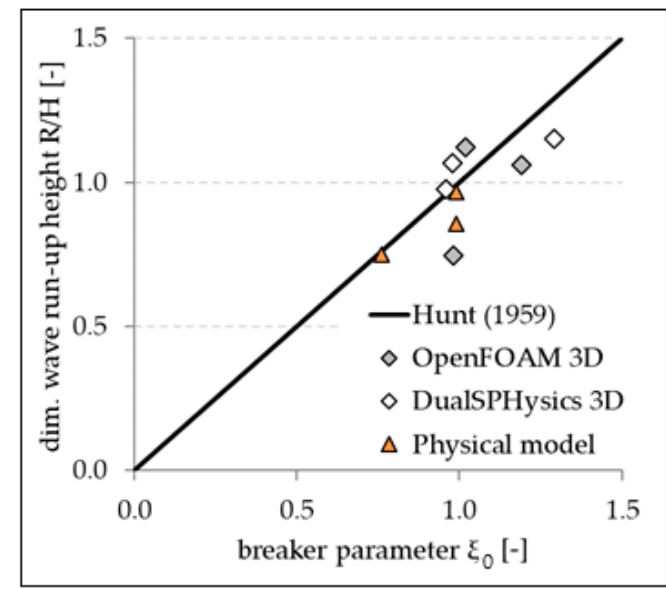

(a)

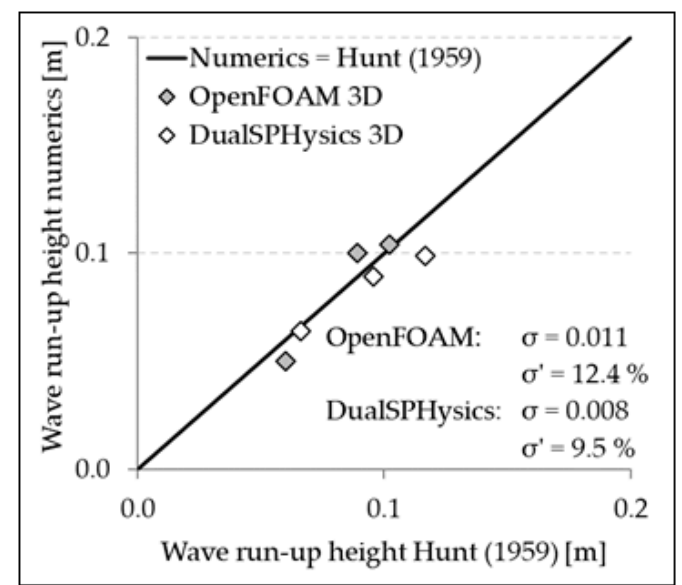

(b)

Figure 4. (a) Wave run-up on a 3D straight dike with perpendicular wave attack (b) Results of the wave run-up calibration on a 3D straight dike compared to Hunt (1959).

Most methods of predicting wave run-up for regular waves are based on the Hunt formula (see Equation (1)), proposed by Hunt (1959) [6]. Hunt proposed a formula based on his experiments on a straight aligned seawall under regular wave attack. He noticed that the non-dimensional relative run-up height, $\mathrm{R} / \mathrm{H}$, from breaking waves is proportional to the slope angle and a function of the square root of the wave steepness, $\mathrm{H} / \mathrm{L}_{0}$, as shown in Equation (1). 


$$
\frac{R}{H}=\frac{\tan \alpha}{\sqrt{\frac{H}{L_{0}}}}=\xi_{0}
$$

where $\mathrm{R}$-wave run-up

$\mathrm{H}$-wave height

$\mathrm{L}_{0}$-deep water wave length

$\alpha$-slope angle

$\xi_{0}$-breaker parameter

In addition to calibration, a convergence study was performed to ensure the sensitivity of both numerical modelling attempts. The DualSPHysics convergence study included the size of the interparticle distance $(\mathrm{dp})(0.01 \mathrm{~m}, 0.02 \mathrm{~m}, 0.03 \mathrm{~m}$ and $0.05 \mathrm{~m}$ for wave parameters shown in Table 2), whereas the appropriate cell size $(0.010 \mathrm{~m}, 0.015 \mathrm{~m}$ and $0.025 \mathrm{~m}$ for wave parameters shown in Table 2), and the influence of Courant number (Courant number: 0.1,1 and 3) were investigated in OpenFOAM. In the case of the simulation in DualSPHysics, the size of the interparticle distance was chosen to be $0.03 \mathrm{~m}$ to reduce the computational time and high data storage volume. A cell size of $0.025 \mathrm{~m}$ was chosen for further analysis in OpenFOAM. The Courant number was chosen to be 1.0 for analysis so that the fluid particles could move maximally one cell within one-time step. The chosen mesh size and interparticle size show reasonably good agreement for wave run-up results in accordance with Hunt's formula (1959) [6] and hence the error does not exceed $\pm 15 \%$.

\subsection{Numerical Model Set-Up}

A 3D numerical model of 1:6 dike slope with a dike height of $0.7 \mathrm{~m}$ was modelled in a numerical wave basin for both concavely and convexly curved dike. Figure 5 illustrates the 3D models of a convexly and concavely curved dike with its boundaries using DualSPHysics. The dike structure was situated in a wave basin with water all around it just as in the corresponding laboratory tests. The left boundary corresponds to wave generation (piston type) and other boundaries act as wave absorbers. Both active wave absorber and a damping zone as a passive wave absorber were used in the DualSPHysics model. These absorption systems allow generating long time series of waves in relatively short domains with negligible wave reflection (Altomare et al., 2017) [23]. The curved dike was split into three parts: The curvature (center part), right (lee side) and left (luv side) dike flanks. The rear side of the convex dike was filled with solid to minimize the computational time. Depending on the angle of wave attack and opening angle, the length of the dike flanks varies from $4 \mathrm{~m}$ to $6 \mathrm{~m}$ in order to reduce simulation time. The DualSPHysics simulations were executed on the Graphics Processing Unit (GPU) "ZOTAC GeForce GTX 1080 Ti”.

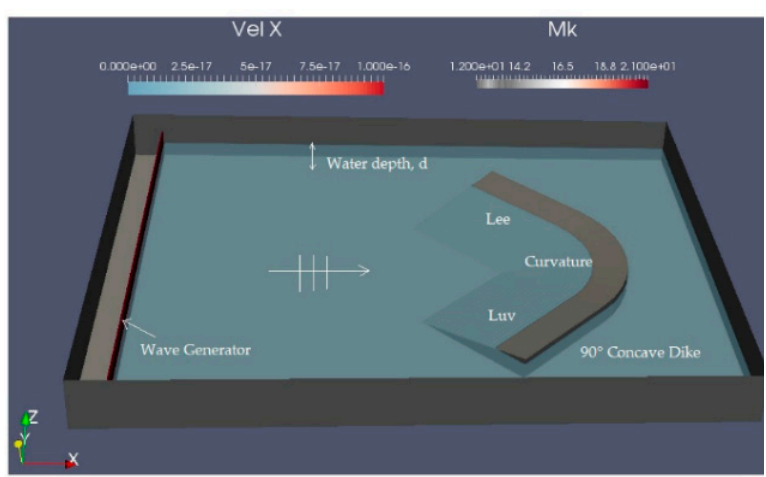

(a)

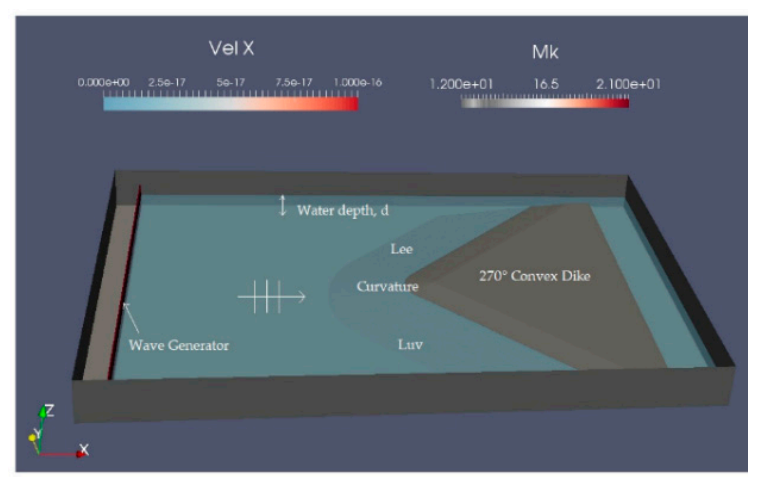

(b)

Figure 5. 3D numerical model of curved dikes in DualSPHysics: (a) $90^{\circ}$ concave dike; (b) $270^{\circ}$ convex dike. 
For simulations with an oblique wave attack, either the wave generation can be adapted (generate oblique waves) or the dike structure can be rotated. To avoid diffraction areas when generating oblique waves, the dike structures are rotated in both numerical models.

\subsection{Transformation Processes on a Curved Dike}

Unlike the transformation processes on straight dikes that mainly include reflection, refraction, shoaling and breaking, additional effects appear at curved dikes. At convex corners, waves are firstly refracted (see Figure 6a) and concentrated at the curvature until they break (see Figure 6b) and then turn towards the dike flanks (see Figure 6c) where they finally superimpose with the incoming waves resulting in wave rollers (see Figure 6d). At concave corners, waves first encounter the dike flank (see Figure 7a) and then are redirected towards the curvature where they interact with further incoming waves influencing the wave breaking process (see Figure $7 \mathrm{~b}$ ) and finally inducing a rip current (see Figure 7d). Along with these complex transformation processes, an irregular wave run-up evolution along the dike line occurs. This pattern for convex and concave shaped dikes is applicable for the respective opening angle shown in Figures 6 and 7. This may vary and the transformation processes are strongly dependent on the wave parameters, angle of wave attack and opening angle.
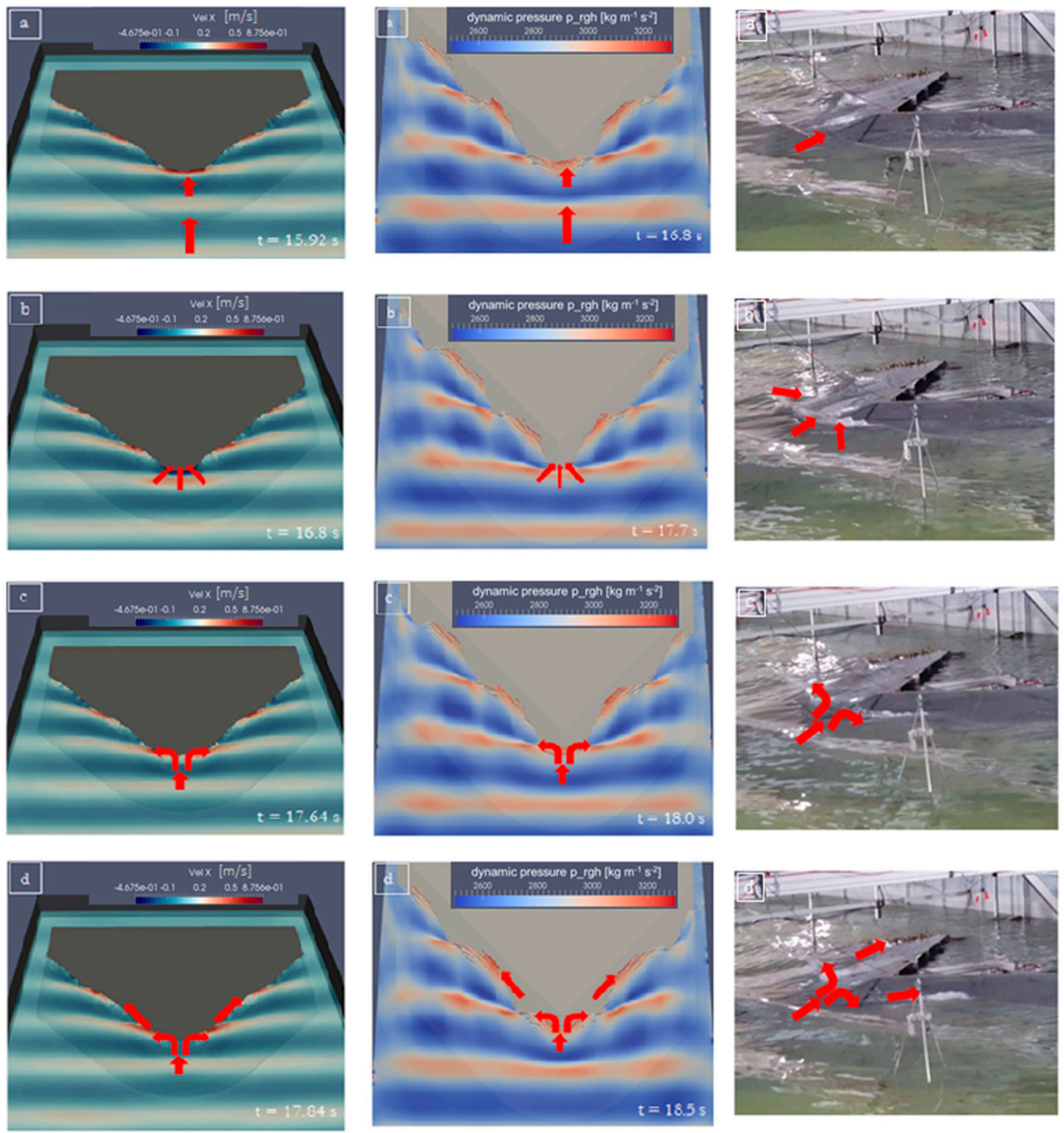

Figure 6. Wave transformation processes on a $270^{\circ}$ convexly curved dike (Left: DualSPHysics, Middle: OpenFOAM, Right: Physical model); $H=0.10 \mathrm{~m}, T=1.46 \mathrm{~s}, \beta=0^{\circ}$. 
The wave transformation processes on a concavely curved dike profile are almost the same in the numerical and physical model. Figure 7a shows the slope-parallel wave breaking of wave $A$ until this is breaking in the corner of the concavely curved dike profile (b) causing a wave run-up. The wave run-down (c) of wave $A$ causes a prematurely wave breaking of wave $B$. The wave run-down is forming of a recycling jet of water in the dike corner $(d)$, which is interacting with wave $C$.
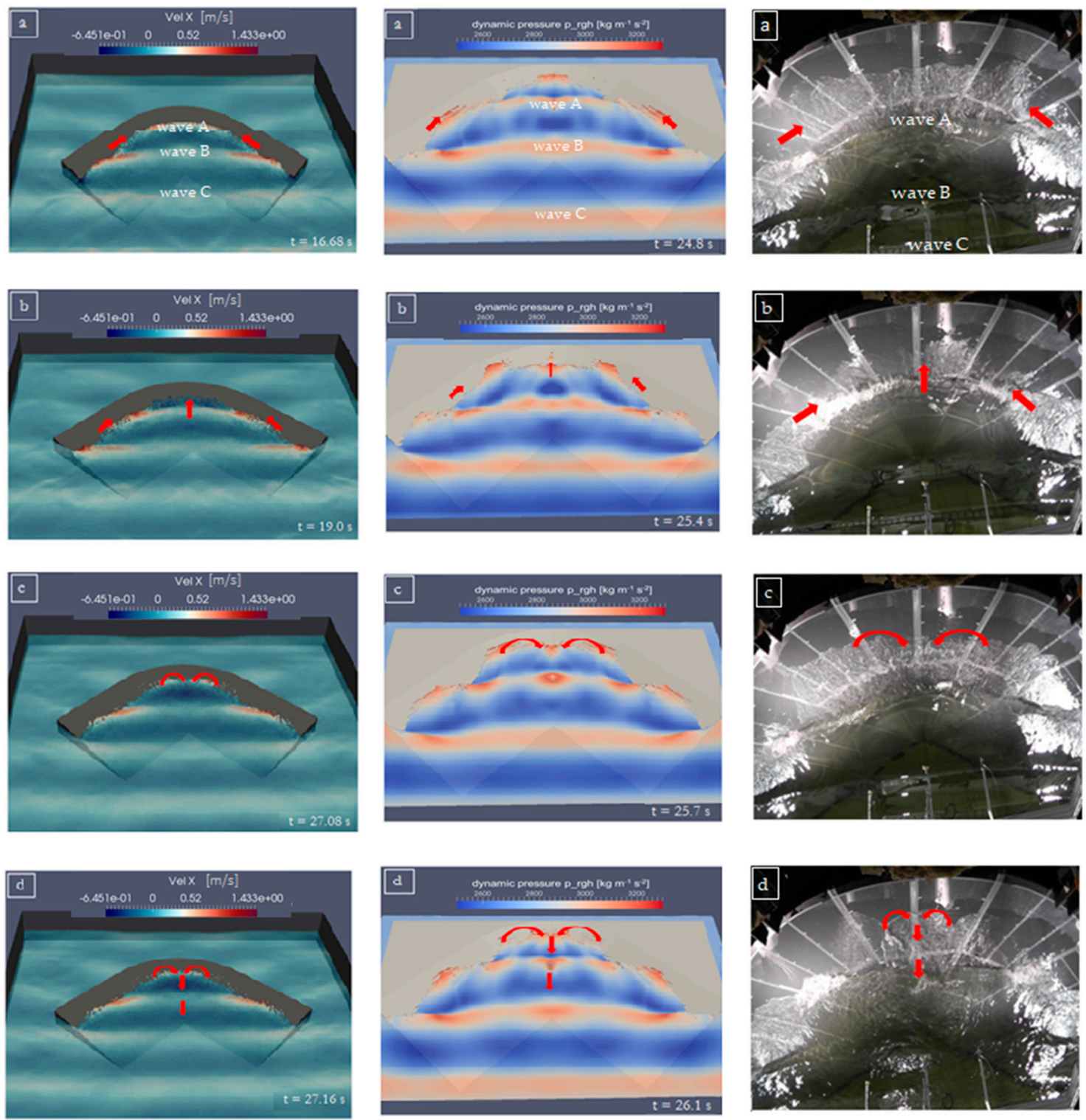

Figure 7. Wave transformation processes on a $90^{\circ}$ concavely curved dike (Left: DualSPHysics, Middle: OpenFOAM, Right: Physical model); $H=0.10 \mathrm{~m}, T=1.46 \mathrm{~s}, \beta=0^{\circ}$.

\section{Analysis Approach}

The effect of wave run-up due to oblique wave attack can be expressed by the influence factor $\gamma_{\beta}$, (EurOtop, 2018) [1].

$$
\gamma_{\beta}=\frac{R_{\text {influence }}}{R_{\text {no influence }}}=\frac{R_{\beta i}}{R_{\beta=0^{\circ}}}
$$

The straight dike analysis is validated for influence factor $\gamma_{\beta}$ in both the numerical and physical models. Figure 8 gives the influence factor $\gamma_{\beta}$ from numerical simulations, the physical model tests and literature plotted against the angle of wave attack $\beta$. Generally, the influence factor $\gamma_{\beta}$ decreases 
with increasing angle of wave attack. Overall, the influence factors from the physical model tests, DualSPHysics and OpenFOAM reproduce the formula from the literature (Wassing (1957) [24], Van der Meer (1995) [25], Ohle et al. (2003) [26]) very well.

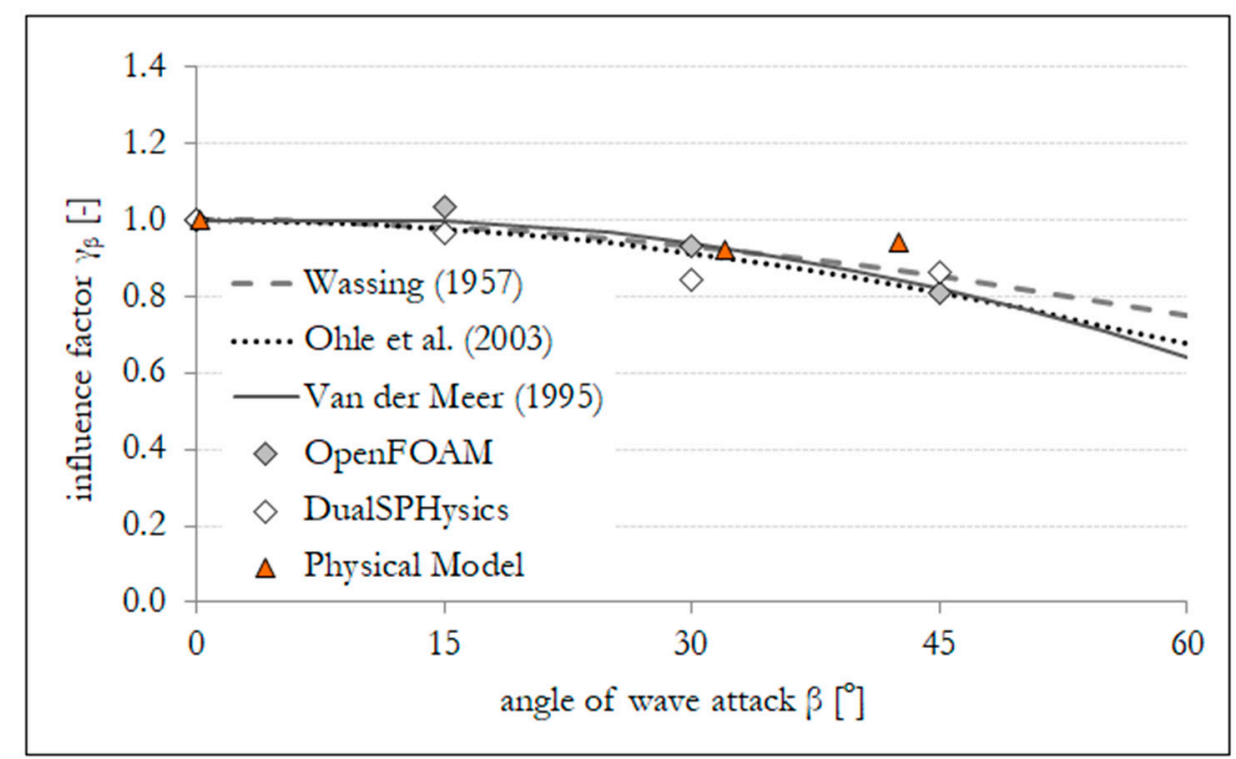

Figure 8. Influence factor $\gamma_{\beta}$ for oblique, regular wave attack from numerical simulations and the literature.

To determine the influence of curvature along a coastal dike line, a new influence factor is introduced. This influence factor $\gamma_{c}$ based on the influence of curvature is derived similar to the influence factor due to obliquity, $\gamma_{\beta}$ introduced in the EurOtop (2018) [1] (see Equation (2)). Similar to Equation (2), the run-up measurements from the curved dike that have an influence due to the curvature are compared to measurements from the straight dike that have no influence due to the curvature by using an influence factor $\gamma_{c}$. The correction factor describing the influence of curvature $\gamma_{c}$ which is defined as follows, is implemented for the analysis.

$$
\gamma_{c}=\frac{R_{\text {influence }}}{R_{\text {no influence }}}=\frac{\left[R /\left(H \times \xi_{0}\right)\right]_{\beta, \alpha_{d}}}{\left[R /\left(H \times \xi_{0}\right)\right]_{\beta, \alpha_{d}=180^{\circ}}}
$$

Based on this new influence factor $\gamma_{c}$ the further analyses for convex and concave dikes are carried out.

\section{Results and Discussion}

The wave run-up on convexly and concavely curved dikes for regular waves under both perpendicular and oblique wave attack is analyzed at the center of curvature and the results are summarized in the following. The wave run-up heights from the convexly and concavely curved dikes are compared to the straight dike by using Equation (3).

Figure 9 shows the influence of the curvature in the dike line on wave run-up for perpendicular wave attack. The bars in Figure 9 represent the standard deviation of different set of wave parameters investigated in numerical and physical model respectively. For convexly curved dikes $\left(\alpha_{d}=210^{\circ}\right.$ to $270^{\circ}$ ), a higher run-up was observed for larger opening angles at the center of curvature. The wave energy focuses on the corner caused by wave refraction over the slope. For large opening angles $\left(\alpha_{d}=270^{\circ}\right)$ the increase of the wave run-up derived from physical model tests is larger than calculated with the numerical models. In case of concavely curved dikes $\left(\alpha_{d}=90^{\circ}\right.$ to $\left.150^{\circ}\right)$, wave run-up increases at the center of curvature as the opening angle decreases. The results from OpenFOAM and the physical model tests for a concavely curved dikes are almost in line, whereas the wave run-up calculated with DualSPHysics is lower for $\alpha_{d}=90^{\circ}$ and $120^{\circ}$. 


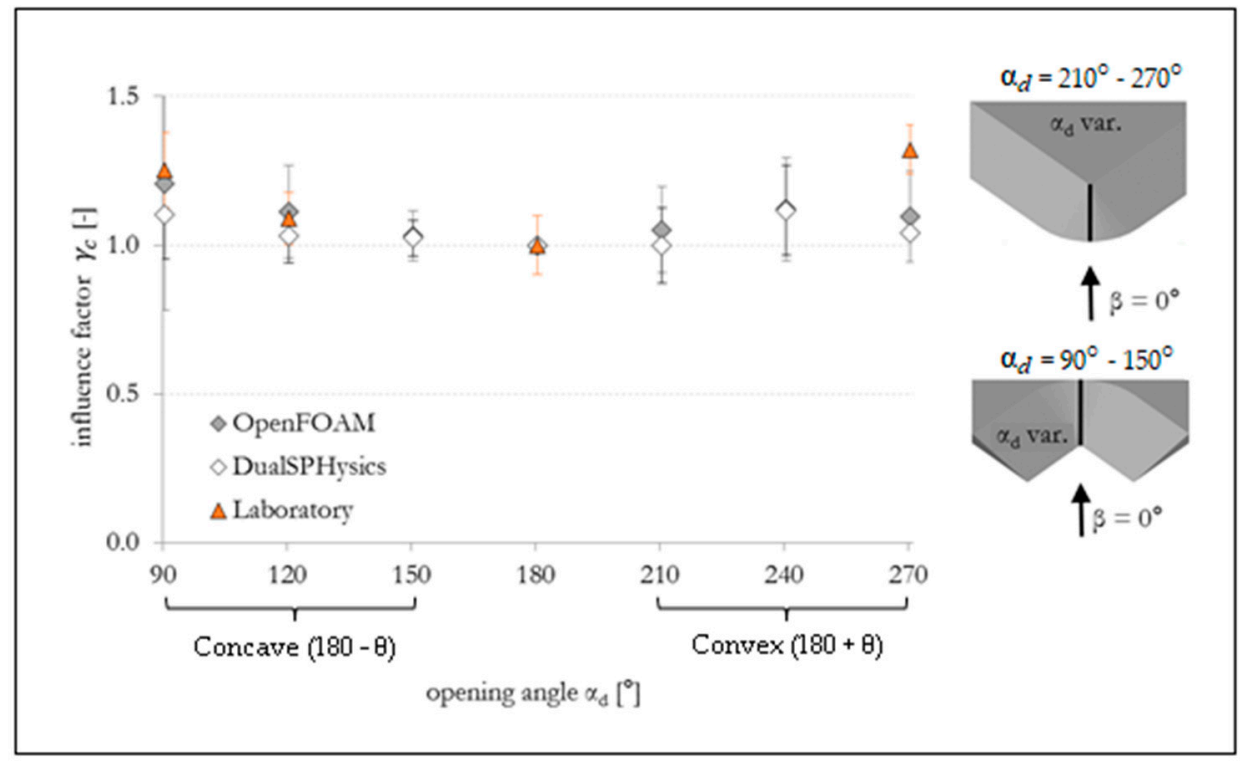

Figure 9. Influence of a curvature in the dike line on wave run-up for perpendicular wave attack-studied position: center of curvature.

Figure 10 shows the influence of curvature in the dike line on wave run-up for a $30^{\circ}$ oblique wave attack. The standard deviation of various set of wave parameters from respective numerical and physical model is also included as bars in Figure 10. For convexly curved dikes $\left(\alpha_{d}=210^{\circ}\right.$ to $\left.270^{\circ}\right)$, a mild increase in wave run-up at the center of the curvature is observed for larger opening angles except for $\alpha_{d}=210^{\circ}$ in DualSPHysics simulations. Nevertheless, the increase is very little and data scatter around $\gamma_{c}=1.0$. Similarly, at concave corners, a slight increase in wave run-up was noticed at $\alpha_{d}=90^{\circ}$. For $\alpha_{d}=120^{\circ}$ the scatter in the wave run-up recorded from the physical model tests is high.

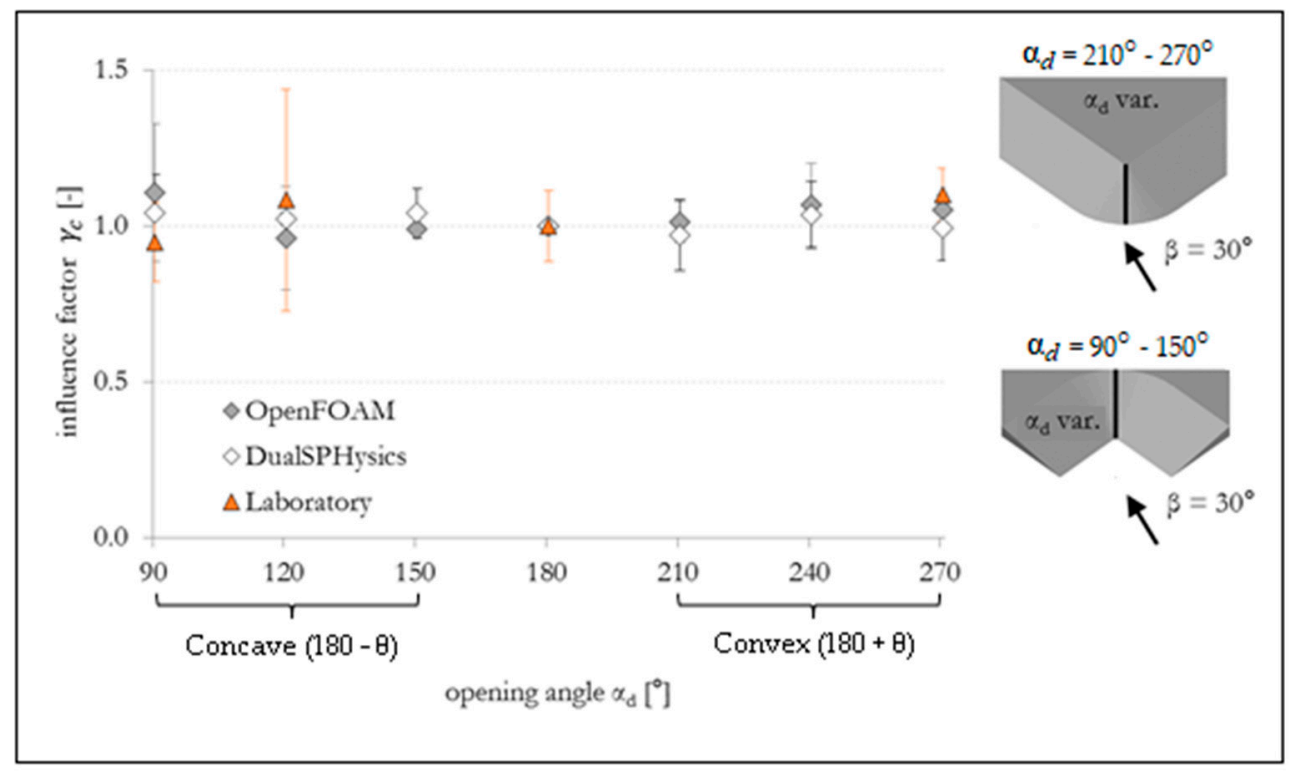

Figure 10. Influence of a curvature in the dike line on wave run-up for a $30^{\circ}$ oblique wave attack-studied position: center of curvature.

Figure 11 shows the influence of curvature in the dike line on wave run-up for a $45^{\circ}$ oblique wave attack. The bars represent the standard deviation of different wave parameters from respective numerical and physical model in Figure 11. For convexly curved dikes $\left(\alpha_{d}=210^{\circ}\right.$ to $\left.270^{\circ}\right)$, a higher run-up is observed at the center of curvature for larger opening angles. Results from physical model 
tests cause a significantly higher wave run-up compared to the two numerical models for $\alpha_{d}=270^{\circ}$. The extremely high results are due to swash running over the convex curve. For $\alpha_{d}=90^{\circ}$, a very high run-up was observed at the center of the curvature in OpenFOAM simulations under $45^{\circ}$ oblique wave attack. In contrast, in the physical model tests a significantly reduced wave run-up height is observed. This special case $\left(\alpha_{d}=90^{\circ}\right)$ was partially biased by model effects, as the incident waves propagate over the model boundary of the slope (side of the luv slope). As the model boundaries differ in numerical and physical model test runs, a deviation is likely. In general, corresponding data points have to be evaluated with care.

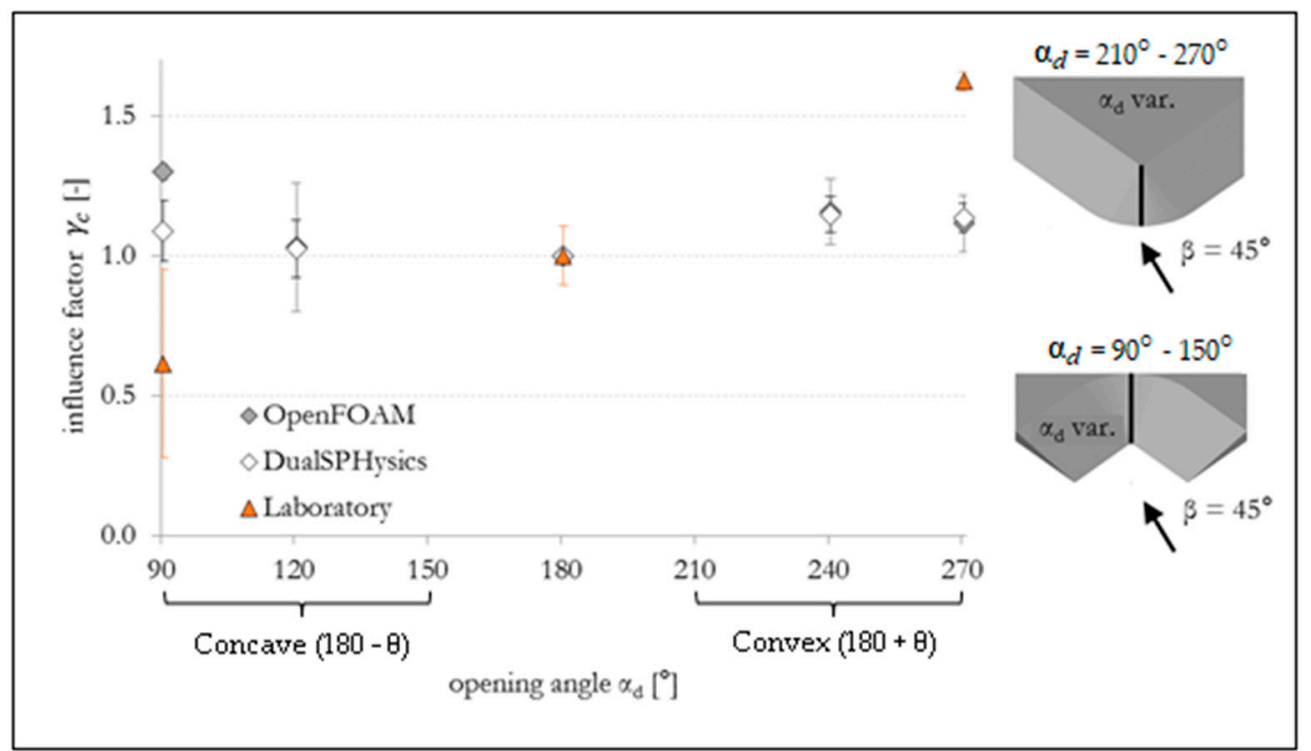

Figure 11. Influence of a curvature in the dike line on wave run-up for a $45^{\circ}$ oblique wave attack-studied position: center of curvature.

The influence factors for the center of curvature, which are derived from the run-up values from both numerical models and physical model, based on Equation (3), are summarised in Table 3. These values confirm that there is an influence in curvature on wave run-up. Future work will endeavour to derive a mathematical expression for the influence of curvature after performing some additional test cases.

Table 3. Influence factors for curvature $\gamma_{c}$ for different opening angles with different angles of wave attack.

\begin{tabular}{|c|c|c|c|c|c|c|c|c|c|}
\hline \multirow{3}{*}{$\begin{array}{l}\text { Opening } \\
\text { Angle } \alpha_{\mathrm{d}} \text {. }\end{array}$} & \multicolumn{9}{|c|}{ Influence Factors $\gamma_{c}$ (Position: Center of Curvature) } \\
\hline & \multicolumn{3}{|c|}{$\beta=0^{\circ}$} & \multicolumn{3}{|c|}{$\beta=30^{\circ}$} & \multicolumn{3}{|c|}{$\beta=45^{\circ}$} \\
\hline & $\begin{array}{l}\text { Open } \\
\text { FOAM }\end{array}$ & $\begin{array}{l}\text { Dual } \\
\text { SPH }\end{array}$ & $\begin{array}{l}\text { Phys. } \\
\text { Model }\end{array}$ & $\begin{array}{l}\text { Open } \\
\text { FOAM }\end{array}$ & $\begin{array}{l}\text { Dual } \\
\text { SPH }\end{array}$ & $\begin{array}{l}\text { Phys. } \\
\text { Model }\end{array}$ & $\begin{array}{l}\text { Open } \\
\text { FOAM }\end{array}$ & $\begin{array}{l}\text { Dual } \\
\text { SPH }\end{array}$ & $\begin{array}{l}\text { Phys. } \\
\text { Model }\end{array}$ \\
\hline $90^{\circ}$ & 1.20 & 1.10 & 1.25 & 1.11 & 1.04 & 0.95 & 1.30 & 1.09 & 0.61 \\
\hline $120^{\circ}$ & 1.11 & 1.03 & 1.09 & 0.96 & 0.97 & 1.08 & 1.03 & 1.02 & - \\
\hline $150^{\circ}$ & 1.03 & 1.02 & - & 0.99 & 1.04 & - & - & - & - \\
\hline $180^{\circ}$ & 1.00 & 1.00 & 1.00 & 1.00 & 1.00 & 1.00 & 1.00 & 1.00 & 1.00 \\
\hline $210^{\circ}$ & 1.05 & 1.00 & - & 1.01 & 0.97 & - & - & - & - \\
\hline $240^{\circ}$ & 1.12 & 1.17 & - & 1.07 & 1.04 & - & 1.15 & 1.15 & - \\
\hline $270^{\circ}$ & 1.09 & 1.04 & 1.32 & 1.05 & 1.00 & 1.10 & 1.12 & 1.17 & 1.62 \\
\hline
\end{tabular}

\section{Conclusions and Future Outlook}

This work reports on the influence of convex and concave curves in the dike line on wave run-up for regular wave attack. The investigation was conducted using numerical models and was validated against measurements from physical model tests. The numerical investigation was accomplished 
using DualSPHysics, a meshless model and OpenFOAM, a mesh-based model. A 3D numerical wave basin was set up and calibrated in both numerical models. The reference dike was chosen as a straight dike and further analysis of curved dikes was compared to the straight dike. The numerical analysis includes an estimation of wave run-up and the wave transformation processes at the curvature. For selected cases, reference tests with a physical model were conducted in a 3D wave basin. The analysis was done for both convex and concave curvatures with different opening angles, angles of wave attack and wave parameters for regular waves. From the analysis, it is observed that the underlying hydrodynamic flow processes at curved dike lines show complex wave processes like wave rollers in case of convex shaped dikes and multi-directional transformation processes in the case of concave shaped dikes. A new influence factor $\gamma_{c}$ is introduced to determine the influence of curvature along the coastal dike line. A mild increase in wave run-up at the center of curvature on a curved dike is observed in most of the test cases under perpendicular or oblique wave attack. For perpendicular wave attack clear trends are visible for different opening angles. For inclined wave attack, the influence of the curvature decreases and the run-up for curvatures scatters in the range of straight slopes. Differences between the different numerical and physical approaches can be ascribed by the choice of mesh size in case of OpenFOAM and inter particle distance in case of DualSPHysics. This can be optimized by using advanced hardware tools with the compromise of high computational cost and high data storage capacity. In spite of the possibility to generate irregular waves on the chosen software tool, the investigations were done only for regular waves on both numerical models. This is due to the same fact of being computationally expensive to simulate a statistically useful number of waves (commonly 1000 waves). Future research work aims to investigate the influence of curvatures on wave overtopping numerically due to the advancement in DualSPHysics, which makes possible the measuring of overtopping using a measuring tool called FlowTool. Only initial investigations were made on the dike flanks within this study, and therefore the influence of dike flanks will be further analyzed.

Author Contributions: H.S., T.S. and N.B.K. conceived the research design and enhanced structure of manuscript. S.P.S. and B.S. developed the theory and performed the numerical study. B.S. investigated the numerical model using OpenFOAM and S.P.S. investigated the numerical model using DualSPHysics. M.S. conducted the hydraulic model tests. M.S., S.L., T.S. and N.B.K. analyzed and verified the results from physical model tests. S.L. and T.S. verified the analytical methods. H.S. encouraged S.P.S. to investigate a comparison for the findings from the numerical study with the findings of the physical model tests and supervised the findings of this work. C.A. guided and validated the DualSPHysics model. All authors discussed the results and contributed to the final manuscript.

Funding: This research was funded by Federal Ministry of Education and Research, Germany under ConDyke project (BMBF_03KIS0108). C.A. activity is funded from the European Union's Horizon 2020 research and innovation programme under the Marie Sklodowska-Curie grant agreement No.: 792370.

Conflicts of Interest: The authors declare no conflict of interest. 


\section{Appendix A}

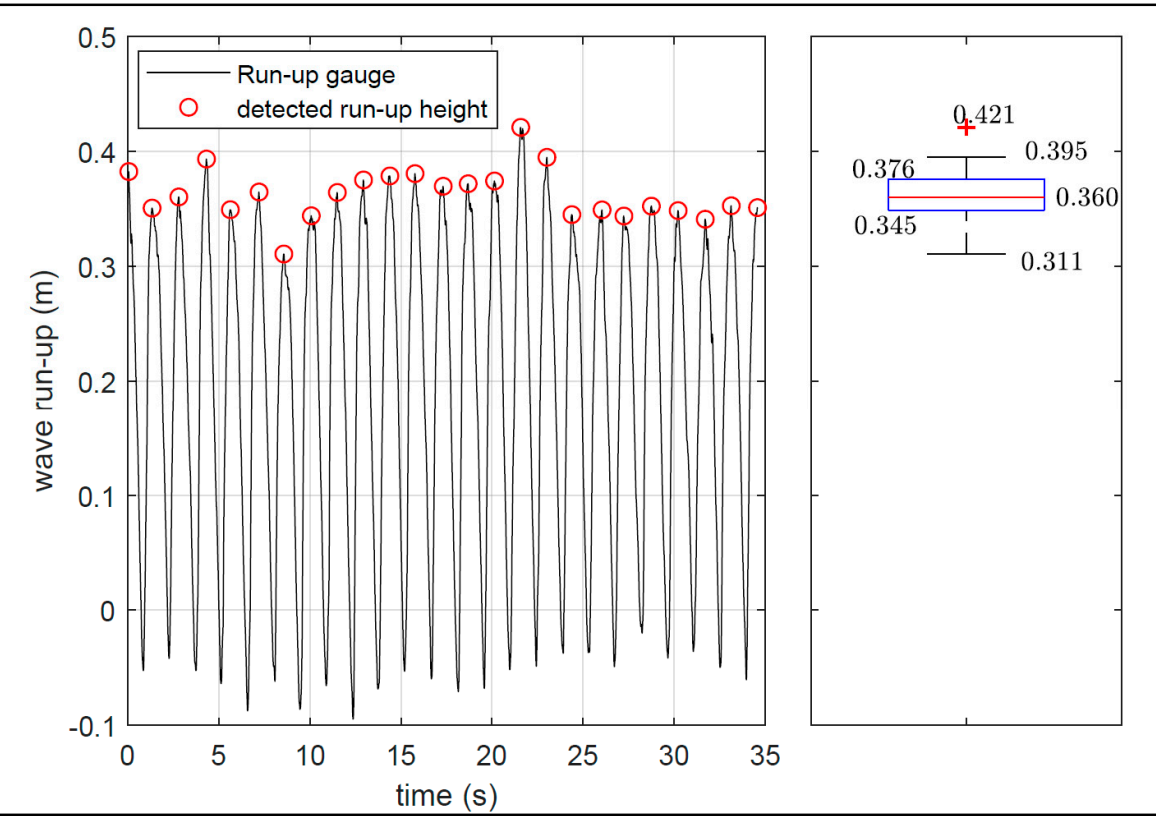

Figure A1. Run-up height calculation from 25 consecutive run-up events.

\section{References}

1. EurOtop. Manual on Wave Overtopping of Sea Defences and Related Structures: An Overtopping Manual Largely Based on European Research, but for Worldwide Application; EurOtop: Brussels, Belgium, 2018.

2. Mayer, R.H.; Kriebel, D.L. Wave run-up on composite slopes and concave beaches. In Proceedings of the 24th Coastal Engineering Conference, Kobe, Japan, 23-28 October 1994; pp. 2325-2339.

3. Goda, Y. Random Seas and Design of Maritime Structures, 2nd ed.; World Scientific: Singapore, 2000.

4. Napp, N.; Bruce, T.; Pearson, J.; Allsop, N.H.W. Violent overtopping of vertical seawalls under oblique wave conditions. In Proceedings of the 29th International Conference on Coastal Engineering, Lisbon, Portugal, 19-24 September 2004.

5. Bornschein, A.; Pohl, R.; Scheres, B.; Wolf, V.; Spano, M. Cornerdike Final Report: Effect of Very Oblique Waves on Wave Run-Up and Wave Overtopping; Cornerdike: Dresden, Germany, 2014; p. 180.

6. Hunt, I.A. Design of seawalls and breakwaters. J. Waterw. Harb. Div. 1959, 85, 123-152.

7. Saville, T. Wave run-up on composite slopes. In Proceedings of the 6th International Conference on Coastal Engineering, Gainesville, FL, USA, December 1957; pp. 691-699. Available online: https://icce-ojs-tamu.tdl. org/icce/index.php/icce/article/view/2050/1722 (accessed on 28 June 2019).

8. Holman, R. Extreme value statistics for wave run-up on a natural beach. Coast. Eng. 1986, 9, 527-544. [CrossRef]

9. Mase, H. Random wave run-up height on gentle slope. J. Waterw. Port Coast. Ocean Eng. 1989, 115, 649-661. [CrossRef]

10. Stockdon, H.F.; Holman, R.A.; Howd, P.A.; Sallenger, A.H. Empirical parameterization of setup, swash, and run-up. Coast. Eng. 2006, 53, 573-588. [CrossRef]

11. Di Lucco, D.; Benassai, G.; Budillon, G.; Mucerino, L.; Montella, R.; Puglise Carratelli, E. Wave run-up prediction and observation in a micro-tidal beach. Nat. Hazards Earth Syst. Sci. 2018, 18, 2841-2857. [CrossRef]

12. Crespo, A.J.C.; Dominguez, J.M.; Rogers, B.D.; Gomez-Gesteira, M.; Longshaw, S.M.; Canelas, R.; Vocondio, R.; Barreiro, A.; Garcia-Feal, O. DualSPHysics: Open-source parallel CFD solver based on smoothed particle hydrodynamics (SPH). Comput. Phys. Commun. 2015, 187, 204-216. [CrossRef]

13. Monaghan, J.J.; Gingold, R.A. Smoothed particle hydrodynamics: Theory and application to non-spherical stars. Mon. Not. R. Astron. Soc. 1977, 181, 375-389. 
14. Meringolo, D.; Aristodemo, F.; Veltri, P. SPH numerical modeling of wave-perforated breakwater interaction. Coast. Eng. 2015, 101, 48-68. [CrossRef]

15. Altomare, C.; Tagliafierro, B.; Suzuki, T.; Crespo, A.J.C.; Briganti, R. Relaxation Zone Method in SPH-based Model Applied to Wave-Structure Interaction. In Proceedings of the Twenty-eighth International Ocean and Polar Engineering Conference, Sapporo, Japan, 10-15 June 2018.

16. Jacobsen, N.G.; Fuhrman, D.R.; Fredsoe, J.A. A wave generation toolbox for the open-source CFD library: OpenFOAM. Int. J. Numer. Methods Fluids 2012, 70, 1073-1088. [CrossRef]

17. Higuera, P.; Lara, J.L.; Losada, I.J. Realistic wave generation and active wave absorption for Navier-Stokes models: Application to OpenFOAM. Coast. Eng. 2013, 71, 102-118. [CrossRef]

18. Crespo, A.J.C.; Dominguez, J.M.; Gesteira, M.G.; Barreiro, A.; Rogers, B.D.; Longshaw, S.; Canelas, R.; Vacondio, R.; Altomare, C. DualSPHysics User Guide: User Guide for DualSPHysics Code. DualSPHsics_v4.0: 2016. Available online: https://github.com/DualSPHysics/DualSPHysics/wiki (accessed on 11 September 2018).

19. DualSPHysics Website: DualSPHysics. Available online: http://www.dual.sphysics.org/ (accessed on 11 September 2018).

20. OlaFoam Reference Manual. Available online: https://github.com/phicau/OLAFOAM (accessed on 11 September 2018).

21. OpenFOAM. OpenFOAM User Guide: OpenFOAM-The Open Source CFD Toolbox-User Guide. OpenFOAM version_3.0.1: 2015. Available online: http://scc.acad.bg/ncsa/articles/library/Library2016_ Supercomputers-at-Work/Computational_Fluid_Dynamic/OpenFOAM/Open\%20FOAM\%20UserGuide\% 202015.pdf (accessed on 28 June 2019).

22. OpenFOAM Website: About OpenFOAM. Available online: www.openfoam.com (accessed on 11 September 2018).

23. Altomare, C.; Dominguez, J.M.; Crespo, A.J.C.; Gonzalez-Cao, J.; Suzuki, T.; Gomez-Gesteira, M.; Troch, P. Long-crested wave generation and absorption for SPH-based DualSPHyics model. Coast. Eng. 2017, 127, 37-54. [CrossRef]

24. Wassing, F. Model investigations of wave run-up carried out in the Netherlands during the last twenty years. In Proceedings of the 6th International Conference on Coastal Engineering, Gainesville, FL, USA, December 1957. Available online: https://icce-ojs-tamu.tdl.org/icce/index.php/icce/article/view/2050/1722 (accessed on 28 June 2019).

25. Van der Meer, J.W.; Janssen, J.P.F.M. Wave run-up and wave overtopping at dikes. Wave Forces Inclin. Vert. Wall Struct. ASCE 1995, 1, 1-27.

26. Ohle, N.; Daemrich, K.F.; Zimmermann, C.; Möller, J.; Schüttrumpf, H.; Oumeraci, H. Schräger Wellenauflauf an seedeichen. Franzius Mitt. 2003, 89, 106-153.

(C) 2019 by the authors. Licensee MDPI, Basel, Switzerland. This article is an open access article distributed under the terms and conditions of the Creative Commons Attribution (CC BY) license (http://creativecommons.org/licenses/by/4.0/). 